\title{
Condensed tannin changes along the digestive tract in lambs fed with sainfoin pellets or hazelnut skins
}

Article

Accepted Version

Quijada, J., Drake, C., Gaudin, E., El-Korso, R., Hoste, H. and Mueller-Harvey, I. (2018) Condensed tannin changes along the digestive tract in lambs fed with sainfoin pellets or hazelnut skins. Journal of Agricultural and Food Chemistry, 66 (9). pp. 2136-2142. ISSN 1520-5118 doi:

https://doi.org/10.1021/acs.jafc.7b05538 Available at https://centaur.reading.ac.uk/75832/

It is advisable to refer to the publisher's version if you intend to cite from the work. See Guidance on citing.

To link to this article DOI: http://dx.doi.org/10.1021/acs.jafc.7b05538

Publisher: American Chemical Society

All outputs in CentAUR are protected by Intellectual Property Rights law, including copyright law. Copyright and IPR is retained by the creators or other copyright holders. Terms and conditions for use of this material are defined in the End User Agreement. 


\section{CentAUR}

Central Archive at the University of Reading

Reading's research outputs online 
Condensed tannin changes along the digestive tract in lambs fed with sainfoin pellets or hazelnut skins

Jessica Quijada ${ }^{\dagger, \xi^{*}}$, Christopher Drake ${ }^{\#}$, Elodie Gaudin ${ }^{\dagger, \S, \Delta}$, Ramzi El-Korso ${ }^{\dagger, \S}$, Hervé Hoste $^{\dagger, \S}$, Irene Mueller-Harvey

${ }^{\dagger}$ INRA, UMR 1225, 23 Chemin des Capelles, Toulouse F-31076, France

${ }^{\S}$ Université de Toulouse, ENVT, 23 Chemin des Capelles, Toulouse F-31076, France

${ }^{\#}$ School of Agriculture, Policy and Development, University of Reading, , P.O. Box 236, Reading RG6 6AT, United Kingdom

${ }^{\Delta}$ MG 2 MIX. La Basse Haye, Châteaubourg 35220, France.

*corresponding author:

E-mail: jessicaquijada7@gmail.com (JQ) 


\section{Abstract}

2 The variable anthelmintic efficacy of condensed tannins (CT) against gastrointestinal nematodes

3 may depend on CT concentration, composition or fate along the digestive tract. We analyzed CT

4 concentration and composition by acetone-HCl-butanol and thiolysis coupled to HPLC-MS in

5 digesta and feces of lambs. Lambs had been infected with Haemonchus contortus and

$6 \quad$ Trichostrongylus colubriformis and received sainfoin pellets and hazelnut skins of contrasting

7 prodelphinidin/procyanidin ratios. The digesta and feces had lower CT concentrations than the

8 original feeds, but similar concentration patterns across the digestive compartments. The changes

9 in assayable CT concentrations between rumen, abomasum and small intestine may be due to

10 complex formation between CT and other dietary components. However, the large CT

11 disappearance (61-85\%) from feed to feces could also indicate that CT may have been structurally

12 modified, degraded or absorbed during digestion. Interestingly, there were no changes in the

13 structural features of assayable CT in the digesta.

14 Keywords: condensed tannins, nematode, Onobrychis viciifolia, Corylus avellana, flavan-3-ols, 15 acetone-HCl-butanol, thiolysis, HPLC-MS 


\section{Introduction}

17 Tannins are polyphenolic plant compounds and can confer beneficial effects on animal nutrition

18 and health, with anthelmintic (AH) effects being of particular interest. ${ }^{1,2}$ Therefore, tannin-

19 containing resources represent a model to explore the concept of nutraceuticals for controlling

20 gastrointestinal nematodes in ruminants. ${ }^{1}$ Proanthocyanidins or condensed tannins (CT) are

21 oligomeric or polymeric flavan-3-ols, where (epi)catechin and (epi)gallocatechin are the most

22 widespread subunits and these give rise to procyanidin (PC) and prodelphinidin (PD) tannins,

23 respectively. In addition, a few plants also contain CT with galloylated flavan-3-ol subunits. . $^{3-5}$

24 It is often assumed that many of the positive effects of CT in terms of animal health and nutrition

25 are based on their protein binding capacity and possibly also on their antioxidant activities. ${ }^{2,6}$

26 Formation of CT-protein complexes is thought to cause a shift from urinary to fecal N-excretion,

27 but with a few CT-containing diets this shift can also lead to better dietary protein utilization and,

28 therefore, animal production. ${ }^{5,7,8}$ In addition, dietary CT can also decrease ruminal

29 methanogenesis ${ }^{9-11}$ and exert anthelmintic activities. ${ }^{1,2,12,13}$

30 Our interests focus on the anthelmintic (i.e. antiparasitic) activity of CT against gastrointestinal

31 nematodes both in vitro and in vivo. ${ }^{1,13}$ Although some in vitro and in vivo results suggest that CT

32 act via a dose-dependent anthelmintic response, ${ }^{14-18} \mathrm{CT}$ quantity is not always related to

33 anthelmintic activity. ${ }^{19,20}$ Indeed, recent evidence indicates that CT structural compositions are

34 important for understanding their anthelmintic activities against parasites from cattle, ${ }^{21}$ small

35 ruminants $^{22}$ and pigs. ${ }^{23}$ Of particular interest are polymer size in terms of mean degree of

36 polymerization $(\mathrm{mDP})$ and the composition of monomeric flavan-3-ol subunits (i.e. PD/PC ratio),

37 which can modulate their anthelmintic effects. 
38 Recent evidence from both in vitro and in vivo studies suggests that anthelmintic effects vary

39 against gastrointestinal nematode $\operatorname{species}^{24}$ and depend on whether they inhabit the abomasum or

40 the small intestine. Variations with regard to gastrointestinal nematode species have been described

41 in vitro. For example, Moreno-Gonzalo et al. ${ }^{18,25}$ evaluated the anthelmintic effect of heather

42 (Ericaceae) extracts on the exsheathment process of $T$. circumcincta, $H$. contortus and $T$.

43 colubriformis infective L3 larvae using the larval exsheathment inhibition assay (LEIA). The EC 50

44 results showed a higher susceptibility for the intestinal T. colubriformis than for the two abomasal

45 species.

46 On the other hand, the effects on gastrointestinal nematodes seem to depend also on the local

47 conditions related either to the host species and/or the local digestive conditions, e.g. whether the

48 worms inhabit the stomach or the small intestine. For example, experimentally infected sheep

49 showed a strong anthelmintic effect with quebracho CT against two intestinal species (Nematodirus

50 battus and Trichostrongylus colubriformis) in terms of lower adult worm burden and female

51 fecundity; however, there was no anthelmintic effect against two abomasal species (Teladorsagia

52 circumcincta and Haemonchus contortus). ${ }^{14}$ In contrast, the same CT (i.e. quebracho) fed to goats

53 reduced the $T$. colubriformis worm burden and $H$. contortus fecundity but there were no changes

54 for $T$. circumcincta. ${ }^{26,27}$

55 To explain these variations against gastrointestinal nematodes, two hypotheses can be proposed: i)

56 anthelmintic activity stems from a species-specific response or ii) there are differences in CT

57 activity along the digestive tract and the local environmental conditions (e.g. $\mathrm{pH}){ }^{28,29}$

58 For example, with regard to the first hypothesis, when purified CT fractions from 15 different

59 plants were evaluated in vitro with the LEIA, Quijada et al. ${ }^{22}$ observed that nematode species 
60 showed different in vitro susceptibilities to CT since lower $\mathrm{EC}_{50}$ were recorded for $H$. contortus

61 (more susceptible) than T. colubriformis. This also depended on the CT composition. Namely,

62 anthelmintic activity against $H$. contortus (an abomasal species) could be linked to two structural

63 features, mDP-values and PD/PC ratios, whereas for the small-intestinal worm, T. colubriformis,

64 only the PD/PC ratio was important. Similar findings on differences in susceptibility between

65 abomasal and intestinal species have also been obtained in vitro with gastrointestinal nematodes of 66 cattle. $^{20}$

67 Up to now, very few studies have addressed the second hypothesis by measuring CT concentrations

68 or activities along the ruminant gut, ${ }^{28-30}$ and no study has compared the effects of CT quality along

69 the gut. Therefore, the present study sought to evaluate the changes of two different CT types from

70 sainfoin plant pellets and hazelnut skins during their passage along the digestive tract of sheep.

71 This study focused i) on CT quantity (concentration) and ii) on CT quality (composition in terms

72 of $\mathrm{PD} / \mathrm{PC}$ ratios and $\mathrm{mDP}$ ) in order to assess whether these could explain their in vivo anthelmintic

73 activities in lambs, which were experimentally infected with $H$. contortus and T. colubriformis.

\section{Materials and Methods}

\section{Trial site}

76 The experiment was carried out at ENVT (National Veterinary School of Toulouse) in the 77 southwest of France $\left(43^{\circ} 35^{\prime} 59^{\prime}, \mathrm{N}, 1^{\circ} 22^{\prime} 41^{\prime}, \mathrm{E}\right)$. The facilities hosting the animals and trial 78 performance met and was approved by the French ethical and welfare rules (Comité d'éthique en 79 expérimentation animale agreement, Science et Santé Animales SSA $N^{\circ} 115$ of December 15, 80 2014). Each group was housed in experimental facilities with concrete floors that had separated 81 boxes of ca. $12 \mathrm{~m}^{2}$ each. All animals had ready access to water. 


\section{Animals}

83 Twenty-seven 4-month-old lambs of Tarascon breed were used. They had been raised under

84 helminth-free conditions and tests were negative for strongyle nematode infections (by McMaster

85 technique according to Raynaud, 1970) before the start of the study. Diclazuril (Vecoxan®, 2.5

$86 \mathrm{mg} / \mathrm{mL}$, Lilly-France, Neuilly-sur-Seine, France) was used, twice at three weekly intervals, at the

87 recommended dose of $1 \mathrm{mg} / \mathrm{kg}$ of live weight to prevent coccidian infection. The study was

88 conducted indoors.

\section{Infective larvae}

90 The isolates of either $H$. contortus or $T$. colubriformis were susceptible to anthelmintics. The

91 infective larvae (L3) were cultured from feces of monospecifically infected donor sheep. Larvae

92 were recovered with the Baermann technique and then stored at $4{ }^{\circ} \mathrm{C}$ for 1 month $(H$. contortus $)$ or

934 months (T. colubriformis).

\section{Experimental design}

95 On day 0 (D0), all lambs were orally infected with a single dose of 2000 L3 H. contortus and 2000

96 L3 T. colubriformis. They had access to ad libitum grass hay, mineral block and water and a ration

97 of commercial (tannin-free) pellets. On day 21 (D21) after parasite infection was confirmed by

98 fecal examination, the animals were allocated into three groups of nine lambs, based on

99 experimental diets [hazelnut skin; sainfoin pellets; control (tannin-free) pellets]. The groups were

100 balanced according to sex, live body weight (mean $29.19 \pm 2.71 \mathrm{~kg}$ ), packed cell volume (PCV\%

$101=39.11 \pm 2.38)$ and fecal egg counts $(\mathrm{EPG}=1124.1 \pm 370.8)$. From D24 to D28, lambs were

102 allowed to adapt to their diets. During the experimental period (D28 - D57), the rations were

103 adjusted once based on body weight (D34), to meet animal growth requirements. Therefore, from 
104 D37 to D44 a second adjustment period was used for the three diets in order to reach an optimal

105 intake level of the two CT-containing diets and to maintain isoproteic and isoenergetic levels in all

106 groups. The condition of the animals was monitored on a daily basis after the infection by checking

107 their feeding and movement behavior and by looking for diarrhea symptoms. Once a week the

108 anemia level was measured (i.e. packed cell volume or hematocrit). None of the lambs got severely

109 ill or died during the trial. All lambs were humanely sacrificed under anesthesia, by intravenous

110 injection (3.6 g/lamb) of pentobarbital sodium (Doléthal ${ }^{\circledR}, 182.2 \mathrm{mg} / \mathrm{mL}$, Vétoquinol S.A.,

111 Magny-Vernois, France) on day D57.

112 Experimental feeds

113 Lambs in the experimental group were allocated three different diets. The first group (hazelnut 114 skin) received commercial feed pellets (tannin free) + hazelnut endocarps; the second group 115 (sainfoin) was fed with sainfoin pellets; the third group was the control group and received only 116 commercial, CT-free feed pellets (Passio Ovi Primeur®, Sud Ouest Aliment SOAL, France).

117 During the whole study period (i.e. 57 days), all groups received a fattening (total mixed) ration 118 diet, which was isoproteic, isoenergetic and balanced for $\mathrm{Ca}, \mathrm{P}$ and the $\mathrm{Ca}: \mathrm{P}$ ratio. Additionally, 119 the two CT-diets (i.e. sainfoin pellets and hazelnut skin groups) were fed at equal CT 120 concentrations.

\section{Preparation of digesta and fecal samples}

122 At necropsy, individual digesta samples were retrieved from five lambs (out of nine) per 123 experimental group (i.e. sainfoin pellet; hazelnut skin; control). Whole digesta (200 mL) were taken 124 directly from each organ, i.e. rumen, abomasum or small intestine (ileum) and fecal samples were 
125 collected from the rectum. Each sample was transferred to a $500 \mathrm{~mL}$ container and stored at -20 $126{ }^{\circ} \mathrm{C}$.

127 The frozen digesta or feces were cooled to $-40{ }^{\circ} \mathrm{C}\left(-0.5^{\circ} \mathrm{C} / \mathrm{min}\right)$ for $2 \mathrm{~h}$ (Cryotec, MUT PCCPLS1.5 128 001, France) and freeze-drying was carried out in two phases. Samples were first subjected to a 129 progressive freeze-drying process using the following temperature and pressure program: $-30{ }^{\circ} \mathrm{C}$ $130\left(0.1^{\circ} \mathrm{C} / \mathrm{min}, 0.1 \mathrm{mbar}\right)$, then at $-10{ }^{\circ} \mathrm{C}\left(0.2{ }^{\circ} \mathrm{C} / \mathrm{min}, 0.3 \mathrm{mbar}\right)$ for $19 \mathrm{~h} 45 \mathrm{~min}$, and finally at $-5^{\circ} \mathrm{C}$ $131\left(0.2{ }^{\circ} \mathrm{C} / \mathrm{min}, 0.15 \mathrm{mbar}\right)$ until reaching $-2{ }^{\circ} \mathrm{C}$. The second phase started when samples had reached $132-2{ }^{\circ} \mathrm{C}$. They were then kept at $20{ }^{\circ} \mathrm{C}$ with a pressure of 0.05 mbar for 15 to $20 \mathrm{~h}$ until dry. The 133 freeze-dried digesta or feces were ground in a Retsch impeller SM1 cutting mill (Haan, Germany) 134 to pass a $1 \mathrm{~mm}$ sieve and stored at $-20{ }^{\circ} \mathrm{C}$ until $\mathrm{CT}$ analysis.

\section{Condensed tannin analyses}

\section{Chemicals}

137 Hydrochloric acid (37\%, analytical reagent grade), acetone (analytical reagent grade), butan-1-ol 138 (standard laboratory reagent grade), acetonitrile (HPLC grade), formic acid (HPLC grade), 139 methanol (HPLC grade) were obtained from Fisher Scientific (Loughborough, UK); benzyl 140 mercaptan (BM) from Sigma-Aldrich (Poole, UK), and ultrapure water $\left(\mathrm{MQ} \mathrm{H}_{2} \mathrm{O}\right)$ from a Milli-Q 141 Plus system (Millipore, Watford, UK).

\section{Tannin analysis by acetone-HCl-butanol assay}

143 The acetone-HCl-butanol assay was described by Grabber et al. $^{31}$ and used with a slight 144 modification as described. ${ }^{28}$ All samples (sainfoin pellets, control pellets or hazelnut skin, digesta 145 and feces) and a freeze-dried sainfoin sample, which served as an internal laboratory control, were 146 run in triplicate with each batch of samples. . After adding the reagent $(10 \mathrm{~mL})$ to the samples $(10$ 
$147 \mathrm{mg}$ ), the tubes were left at room temperature for 1 hour to check for the possibility of flavan-4-ol 148 or flavan-3,4-diol interference. The tubes were then heated at $70{ }^{\circ} \mathrm{C}$ for 2.5 hours in the dark. After 149 cooling to room temperature and centrifugation spectra were recorded between 450 and $650 \mathrm{~nm}$ on 150 a Jasco V-530 spectrophotometer (Jasco UK, Dunmow, UK). The acetone-HCl-butanol reagent 151 was used as a blank. The absorbance at the peak maximum was determined and converted to CT 152 concentration based on calibration curves derived from a purified prodelphinidin standard, isolated 153 from Lespedeza cuneata plants, for sainfoin samples and a purified procyanidin standard, isolated 154 from Tilia flowers, for hazelnut samples. ${ }^{22}$ The CT concentration was reported as g CT/100 g on a 155 dry weight (DW) basis.

\section{Tannin analysis by thiolysis}

157 The thiolysis reaction was carried out as described previously. ${ }^{32}$ The reaction products were 158 identified by HPLC-MS analysis ${ }^{23,28}$ and quantified based on peak areas at $280 \mathrm{~nm}$ using published 159 flavan-3-ol response factors against taxifolin. ${ }^{3,32}$ This provided information on CT concentration 160 (\% CT) and size (mean degree of polymerization, mDP), molar percentages of prodelphinidins 161 (PD) and procyanidins (PC) within CT, and molar percentages of trans- vs cis-flavan-3-ols (trans 162 and $c i s) .{ }^{3}$ Samples were also analyzed for free flavan-3-ols, but none were detected.

\section{Statistical Analyses}

164 Non-parametric analysis (Kruskal-Wallis and Kolmogorov-Smirnov test) was applied to CT values 165 (CT concentration, mDP, PC, PD, cis, trans) per sample type (i.e. digesta or feces) as determined 166 by each CT assay (acetone-HCl-butanol or thiolysis) and flavan-3-ol terminal and extension units. 167 Comparisons were made between 1) the different diet treatments, and 2) the different segments of 168 the digestive tract within each diet treatment group. All statistical analyses were performed using 169 Systat ${ }^{9}$ software (SPSS Ltd). 


\section{Results}

\section{Condensed tannin concentrations in digesta and feces}

172 According to the acetone-HCl-butanol assay, there were no differences $(\mathrm{P}>0.05)$ in the CT-

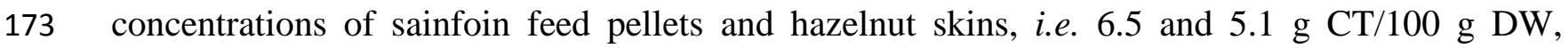

174 respectively (Table 1). As expected the control pellets had no CT. Digesta and fecal samples had 175 significantly lower CT concentrations than the feeds in both the sainfoin- and hazelnut-fed lamb 176 groups (Table 1), i.e. from 1.0 to $2.1 \mathrm{~g} \mathrm{CT} / 100 \mathrm{~g} \mathrm{DW}$. For the lambs of the sainfoin group, these 177 values represented reductions of $84.6 \%, 67.7 \%, 72.4 \%$ and $69.2 \%$ and for the lambs of the hazelnut 178 group, these CT losses were $78.5 \%, 66.7 \%, 76.5 \%$ and $60.8 \%$ for ruminal, abomasal, small 179 intestinal and fecal samples, respectively. Overall, the CT concentrations showed similar patterns 180 in both groups: slightly higher values were measured in the abomasal and fecal samples, and lower values in the ruminal or small intestinal samples. There were no differences in CT concentrations 182 between the sainfoin and hazelnut groups $(\mathrm{P}>0.05)$ but differences were found between the digesta 183 or feces samples within each feed group $(\mathrm{P}<0.05)$.

184 In contrast to the acetone-HCl-butanol assay, the thiolysis reaction gave quite different CT 185 concentrations $(\mathrm{P}<0.01)$ for the sainfoin pellets $(1.7 \pm 1.01 \mathrm{~g} \mathrm{CT} / 100 \mathrm{~g} \mathrm{DW})$ and hazelnut skins

$186(6.3 \pm 1.01 \mathrm{~g} \mathrm{CT} / 100 \mathrm{~g} \mathrm{DW})($ Table 1$)$. The sainfoin group had the highest CT value in the abomasal 187 digesta $(0.7 \pm 0.1 \mathrm{~g} \mathrm{CT} / 100 \mathrm{~g} \mathrm{DW})$, and the hazelnut group in the abomasal and fecal samples (approx. 0.7 $\pm 0.1 \mathrm{~g} \mathrm{CT} / 100 \mathrm{~g} \mathrm{DW}$ ). Thus, apparent CT losses were 85.3\%, 58.8\%, 76.5\% and 76.5\% 189 in the sainfoin group, and $92.1 \%, 88.9 \%, 93.7 \%$ and $88.9 \%$ in the hazelnut group in the rumen, 190 abomasum, small intestine and feces compared to the diets, respectively. Differences were found 191 for the CT concentrations measured by thiolysis between the two types of feeds and between the 192 digesta and fecal sample within each feed-group $(\mathrm{P}<0.05)$. No differences were recorded between 
193 the feed groups when comparing the samples from the same organs $(\mathrm{P}>0.05)$. Once, again thiolysis

194 also did not detect any CT in the samples from the control animals.

\section{CT structural features in digesta and feces}

196 Thiolysis also afforded information on the CT composition in terms of molar percentages of 197 prodelphinidins, procyanidins (or PD/PC ratios), cis- and trans-flavan-3-ols and mean degrees of 198 polymerization (Table 2). The CT in the sainfoin digesta and fecal samples had high percentages 199 of prodelphinidins (i.e. rumen 79.5, abomasum 84.1, small intestine 78.7, and feces $72.4 \%$ ) and 200 cis-flavan-3-ols (i.e. rumen 87.9, abomasum 91.3, small intestine 87.5, and feces 88.9\%), which 201 were similar to the original sainfoin pellets (i.e. PD 74.8 and cis-flavan-3-ols 85.3\%). Due to the 202 low CT concentrations (Table 1), it was not possible to calculate the mDP values in these digesta 203 samples as the peaks of the terminal flavan-3-ol units were too small to be detected. In the hazelnut 204 group, the CT composition was also preserved: hazelnut skins, digesta and fecal samples had high 205 percentages of procyanidins, similar percentages of cis- and trans-flavan-3-ols and similar mean 206 degrees of polymerization (Table 2).

\section{Discussion}

208 This study was carried out to determine the changes in CT concentrations and compositions during 209 the transit of the sainfoin pellet and hazelnut skin diets in the digestive tract of lambs in order to 210 provide a basis for understating the anthelmintic effects of these diets. Our previous research 211 discovered that gastrointestinal parasites that reside in the abomasum tended to be more sensitive 212 to tannins (i.e. lower $\mathrm{EC}_{50}$-values) than parasites that are found in the intestines. ${ }^{22}$ Lambs were fed 213 with two diets that differed in CT compositions: sainfoin pellets had a high PD/PC ratio (75/25) 214 and hazelnut skins had a low PD/PC ratio (28/72). Samples were taken from along the digestive 
215 tract to study CT concentration and compositional changes in the rumen, abomasum, small intestine

216 (ileum) and feces and were compared with the feeds.

217 Given the absence of data on CT changes along the digestive tract, we decided to use two assays

218 that employ different reagents and reaction conditions for the degradation of tannins: the acetone-

$219 \mathrm{HCl}$-butanol reaction uses harsher conditions and is carried out at $70{ }^{\circ} \mathrm{C}$ for $2.5 \mathrm{~h}$ with $5 \% \mathrm{HCl}$ and

$22033 \%$ water, whereas the thiolysis reaction is milder and takes place at $40{ }^{\circ} \mathrm{C}$ for $1 \mathrm{~h}$ with $<1 \% \mathrm{HCl}$

221 in methanol. Previous studies demonstrated that the acetone-HCl-butanol assay can occasionally

222 give higher CT concentrations than the thiolysis assay when plant materials are analyzed. ${ }^{2,33,34}$

223 Condensed tannin contents in digesta and feces

224 There are only a few studies so far that have evaluated changes in CT concentrations in small

225 ruminants and these used a previous, less sensitive, version of the HCl-butanol assay. ${ }^{29,30}$ One

226 recent study also reported thiolysis results for CT concentrations and compositions in digesta from

227 sainfoin-fed cattle, which had been infected with gastro-intestinal nematodes. ${ }^{28}$ To the best of our

228 knowledge, the current study, therefore, presents for the first time CT concentrations and

229 composition in digesta and feces of lambs. The $60 \%$ to $80 \%$ decrease of CT concentrations (by

230 acetone-HCl-butanol) from feeds to digesta or feces was comparable to the ${ }^{14} \mathrm{C}$-labelled CT losses

231 in sheep of $71.1-98.5 \% .^{29}$ Similarly, large decreases in digesta or fecal samples were also

232 described in post-rumen losses in sheep $(85-86 \%)$ and goats $(83 \%){ }^{29,30}$

233 The relatively mild conditions during thiolysis reaction compared to the acetone-HCl-butanol assay

234 may not release all CT from the sample matrix. ${ }^{32}$ In addition it has also been shown that some CT

235 polymers are resistant to degradation with thiols, ${ }^{34,35}$ which may explain the lower CT

236 concentrations detected by thiolysis than by acetone-HCl-butanol in digesta and feces (Table 
237 1). ${ }^{28,33,36}$ Thiolysis also measured much lower CT concentrations than the acetone-HCl-butanol 238 method for the sainfoin pellets (1.7 vs $6.5 \mathrm{~g} \mathrm{CT} / 100 \mathrm{~g} \mathrm{DW}$ ) but surprisingly not for the hazelnut 239 skins (6.3 vs $5.1 \mathrm{~g} \mathrm{CT/100} \mathrm{g} \mathrm{DW).} \mathrm{The} \mathrm{reason} \mathrm{for} \mathrm{this} \mathrm{discrepancy} \mathrm{is} \mathrm{not} \mathrm{clear} \mathrm{and} \mathrm{will} \mathrm{need} \mathrm{further}$ 240 investigation; this finding also illustrates the need for using more than one analytical technique 241 when dealing with unusual matrices in order to probe the biological effects of CT. ${ }^{2}$

242 Despite these differences, both assays revealed a similar pattern (Table 1): the highest CT 243 concentrations were measured in the abomasal samples in both the sainfoin and the hazelnut groups 244 and also in the feces from the hazelnut lamb group. Interestingly, another study that fed sainfoin 245 pellets to cattle also found that CT concentrations were higher in the abomasum (acetone-HCl246 butanol: 5.8\%; thiolysis $2.3 \%$ ) than the rumen (acetone-HCl-butanol: $3.0 \%$; thiolysis: $0.5 \%$ ). ${ }^{28}$ It is 247 well known that CT bind dietary Rubisco protein optimally at a $\mathrm{pH}$ that is close to neutral. ${ }^{2}$ Thus, 248 we hypothesize that dietary proteins are complexed by $\mathrm{CT}$ in the rumen (pH 6-7) and released 249 under the acid conditions in the abomasum $(\mathrm{pH}<3.5){ }^{29}$ Indeed, the results support this 250 explanation: measured concentrations were highest in the abomasum (Table 1) and a possible 251 explanation could be that these CT were not complexed by proteins and thus remained more 252 accessible and reactive in both assays. In fact, Ramsay et al. ${ }^{34}$ also noted that benzyl mercaptan in 253 the thiolysis reagent appeared to react preferentially with extractable rather than tightly bound CT. 254 The increased CT concetrations in feces could be due to the combined action of matrix digestion 255 plus bile acids and $\mathrm{pH}(>7)$ that can disrupt CT-protein complexes. ${ }^{30}$ However, there are also 256 numerous other matrix components with which CT can interact, such as carbohydrates, lipids and 257 intestinal mucosa $a^{5,37-39}$ and further work will be needed to establish the interactions between CT 258 and dietary matrix components. Whilst thiolysis appears to preferentially detect extractable CT, ${ }^{28,34}$ 259 the acetone-HCl-butanol assay appears better able to detect bound CT. ${ }^{34}$ 
260 However, these results also point to considerable CT modification or degradation in the digestive

261 tract of sheep as pointed out previously with sheep, goat, cattle and pig feeding trials. ${ }^{28,29,30,40}$ If

262 CT were inert, CT concentrations would be expected to increase progressively throughout the tract

263 as dietary matrix components are digested and only the undigestible and non-absorbed components

264 would remain. ${ }^{41}$ Mean dry matter digestibilities in sheep are $58 \%$ according to a meta-analysis ${ }^{42}$

265 and, therefore, the CT concentration in feces of sainfoin-fed sheep should have been close to $15 \%$.

266 However, as we could only detect $2 \%$ by the acetone-HCl-butanol assay, it would appear that $87 \%$

267 of the CT could no longer be detected. A cattle study that used the same sainfoin diet and acetone-

$268 \mathrm{HCl}$-butanol assay estimated that ca $50 \%$ of the CT had disappeared. ${ }^{28}$ Considerable losses of CT,

$26929 \%$ by thiolysis and $17 \%$ by acetone-HCl-butanol, were also reported after fermentation of

270 silages $^{34}$ and from the human digestive tract, where the gut microflora caused extensive losses due

271 to CT metabolism. ${ }^{43}$

\section{CT structural features in digesta and feces}

273 The CT compositions in Tables 2 and 3 of sainfoin, (mostly prodelphinidins), and hazelnut skins

274 (mostly procyanidins), agree with literature reports. ${ }^{32,44,45}$ Table 3 lists the monomeric subunits that

275 give rise to prodelphinidins (gallocatechin and epigallocatechin) and to procyanidins (catechin and

276 epicatechin). Once again, there were no significant changes in these flavan-3-ol compositions

277 between the digesta and the sainfoin feed pellets. The molar composition of these flavan-3-ols

278 decreased as follows: EGC > EC > GC > C, which was in line with the literature. ${ }^{45}$ The flavan-3-

279 ol compositions in the hazelnut skins and the corresponding digesta and fecal samples were also

280 not significantly different (Table 3). However, ca. 5\% of the subunits in the hazelnut skins were

281 galloylated, i.e. epicatechin gallate (ECg) and epigallocatechin gallate (EGCg), but none of these 
282 galloylated subunits could be detected in the digesta or feces, which indicated that the esterified 283 gallic acid may have been cleaved from the CT either by esterases or acids in the gut.

284 It can be concluded that the CT compositional features of PD/PC and cis/trans ratios, mean degrees 285 of polymerization, and molar percentages of individual flavan-3-ol subunits were preserved during 286 the digestion in lambs. A similar conclusion was reached after examining the CT composition of 287 ensiled sainfoin. ${ }^{34}$ These results suggested that CT structures per se were not modified during 288 fermentation and digestion - with the exception of esterified gallic acids, which appeared to be 289 cleaved. However, the acetone-HCl-butanol assay measured CT reductions of up to $85 \%$ and 290 thiolysis up to $94 \%$ in digesta and feces (dry weight basis) compared to the original feeds. These 291 CT decreases suggested that there may be similar processes taking place in the ruminant digestive 292 tract as in the colon of monogastric animals. ${ }^{43,47,48}$ In addition, abomasal digesta samples tended to 293 have the highest levels of assayable CT, which could be due to a matrix effect, as CT tend to bind 294 less strongly at acid $\mathrm{pH}$-values to most proteins.

295 These findings lend support to the hypothesis that CT activity is higher in the abomasum than the 296 intestine, which could explain why CT are more effective against abomasal than intestinal parasite 297 species. ${ }^{49}$ However, our data do not provide support for a species-specific response to CT, despite 298 such evidence from in vitro studies with Haemonchus contortus (an abomasal species) and 299 Trichostrongylus colubriformis (an intestinal species). ${ }^{22}$ Our results have now revealed that the CT 300 flavan-3-ol subunit composition was preserved along the digestive tract, hence the higher in vitro 301 biological activity of prodelphinidins can be expected to be maintained under in vivo conditions as 302 long as the overall CT concentration remains sufficiently high.

\section{Abbreviations Used}


304 CT, condensed tannins; PD, prodelphinidins; PC, procyanidins; mDP, mean degree of 305 polymerization; BM, benzyl mercaptan; C, catechin; EC, epicatechin; ECg, epicatechin gallate; 306 EGC, epigallocatechin; EGCg, epigallocatechin gallate; GC, gallocatechin.

\section{Acknowledgments}

308 Assistance from Mrs. Fabienne Picard and Dr Vincent Niderkorn (INRA, UMR 1213 Herbivores, 309 Saint-Genès-Campanelle, France) with freeze-drying of digesta samples is deeply appreciated.

310 Supporting information. Feed nutritional analyses results for each experimental group are shown 311 in regard to composition, fiber content and nutrition values.

\section{Author's contribution}

313 JQ and HH designed and performed the animal experiments. IMH designed the chemical analyses. 314 EG and REK helped in the animal experiment. JQ, HH and IMH analyzed the data and prepared 315 the manuscript. CD, EG, REK contributed reagents, materials and analysis tools. All authors 316 critically read and approved the final manuscript.

\section{Competing interest}

318 The authors declare that they have no competing interests. 


\section{References}

1. Hoste, H; Torres-Acosta, J.F.J.; Sandoval-Castro, C.A.; Mueller-Harvey, I.; Sotiraki, S.; Louvandini, H.; Thamsborg, S.M.; Terrill, T.H. Tannin containing legumes as a model for nutraceuticals against digestive parasites in livestock. Vet. Parasitol. 2015, 212, 5-17.

2. Mueller-Harvey, I.; Bee, G.; Dohme-Meier, F.; Hoste, H.; Karonen, M.; Kölliker, R.; Lüscher, A.; Niderkorn, V.; Pellikaan, W.F.; Salminen, J-P.; Skøt, L.; Smith, L.M.J.; Thamsborg, S.M.; Totterdell, P.; Wilkinson, I.; Williams, A.R.; Azuhnwi, B.N.; Baert, N.; Grosse Brinkhaus, A.; Copani, G.; Desrues, O.; Drake, C.; Engström, M.; Fryganas, C.; Girard, M.; Huyen, N.T.; Kempf, K.; Malisch, C.; Mora-Ortiz, M,.; Quijada, J.; Ramsay, A.; Ropiak, H.M.; Waghorn, G.C. Benefits of condensed tannins in forage legumes fed to ruminants: importance of structure, concentration and diet composition. Crop Sci. 2017. DOI: 10.2135/cropsci2017.06.0369

3. Ropiak, H.M.; Ramsay, A.; Mueller-Harvey, I. Condensed tannins in extracts from European medicinal plants and herbal products. J. Pharm. Biomed. Anal. 2016, 121, 225-231.

4. Hagerman, A. Fifty years of polyphenol-protein complexes. In: Cheynier, V.; Sami-Machado, P.; Quideau, S. (eds) Recent Advances in Polyphenol Research. Vol. No. 3. 1st Edition WileyBlackwell \& Sons, Oxford, UK. 2012, 364 pp.

5. Patra, A.K.; Saxena, J. Exploitation of dietary tannins to improve rumen metabolism and ruminant nutrition. J. Sci. Food Agric. 2011, 91, 24-37.

6. Luciano, G.; Vasta, V.; Monahan, F.J.; López-Andrés, P.; Biondi, L.; Lanza, M.; Priolo, A. Antioxidant status, colour stability and myoglobin resistance to oxidation of longissimus dorsi muscle from lambs fed a tannin-containing diet. Food Chem. 2011, 124, 1036-1042.

7. Buccioni, A.; Pauselli, M.; Viti, C.; Minieri, S.; Pallara, G.; Roscini, V.; Rapaccini, S.; Marinucci, M.T.; Lupi, P.; Conte, G.; Mele, M. Milk fatty acid composition, rumen microbial 
population, and animal performances in response to diets rich in linoleic acid supplemented with 343 chestnut or quebracho tannins in dairy ewes. J. Dairy Sci. 2015, 98, 1145-56.

344 8. Waghorn, G.C.; John, A.; Jones, W.T.; Shelton, I.D. Nutritive value of Lotus corniculatus L. 345 containing low and medium concentrations of condensed tannins for sheep. Proc. New Zeal. 346 Soc. Anim. Prod. 1987, 47, 25-30.

347 9. Bhatta, R.; Saravanan, M.; Baruah, L.; Prasad, C.S. Effects of graded levels of tannin-containing 348 tropical tree leaves on in vitro rumen fermentation, total protozoa and methane production. $J$. 349 Appl. Microbiol. 2015, 118, 557-564.

350 10. Huyen, N. T.; Fryganas, C.; Uittenbogaard, G.; Mueller-Harvey, I.; Verstegen, M.W.A.;

351 Hendriks, W.H.; Pellikaan, W.F. Structural features of condensed tannins affect in vitro

352 ruminal methane production and fermentation characteristics. J. Agr. Sci. 2016, 154, 1474$353 \quad 1487$.

354 11. Liu. H.; Vaddella, V.; Zhou, D. Effects of chestnut tannins and coconut oil on growth 355 performance, methane emission, ruminal fermentation, and microbial populations in sheep. $J$. 356 Dairy Sci. 2011, 94, 6069-6077.

357 12. Zhong, R.Z.; Li, H.Y.; Sun, H.X.; Zhou, D.W. Effects of supplementation with dietary green 358 tea polyphenols on parasite resistance and acute phase protein response to Haemonchus 359 contortus infection in lambs. Vet. Parasitol. 2014, 205, 199-207.

360 13. Hoste, H.; Martinez-Ortiz-De-Montellano, C.; Manolaraki, F.; Brunet, S.; Ojeda-Robertos, N.; 361 Fourquaux, I.; Torres-Acosta, J.F.J.; Sandoval-Castro, C.A. Direct and indirect effects of 362 bioactive tannin-rich tropical and temperate legumes against nematode infections. Vet. $363 \quad$ Parasitol. 2012, 186, 18-27. 
14. Athanasiadou, S.; Kyriazakis, I.; Jackson, F.; Coop, R. Direct anthelmintic effects of condensed tannins towards different gastrointestinal nematodes of sheep: in vitro and in vivo studies. Vet. Parasitol. 2001, 99, 205-219.

15. Brunet, S.; Hoste. H. Monomers of condensed tannins affect the larval exsheathment of parasitic nematodes of ruminants. J. Agric. Food Chem. 2006, 54, 7481-7487.

16. Brunet, S.; Aufrère, J.; El Babili, F.; Fouraste, I.; Hoste, H. The kinetics of exsheathment of infective nematode larvae is disturbed in the presence of a tannin-rich plant extract (sainfoin) both in vitro and in vivo. Parasitology 2007, 134, 1253-1262.

17. Burke, J.M.; Whitley, N.C.; Pollard, D.A.; Miller, J.E.; Terrill, T.H.; Moulton, K.E.; Mosjidis J.A. Dose titration of sericea lespedeza leaf meal on Haemonchus contortus infection in lambs and kids. Vet. Parasitol. 2011, 181, 345-349.

18. Moreno-Gonzalo, J.; Manolaraki, F.; Frutos, P.; Hervás, G.; Celaya, R.; Osoro, K.; OrtegaMora, L.M.; Hoste, H.; Ferre, I. In vitro effect of heather extracts on Trichostrongylus colubriformis eggs, larvae and adults. Vet. Parasitol. 2013, 197, 586-594.

19. Naumann, H.D.; Armstrong, S.A.; Lambert, B.D.; Muir, J.P.; Tedeschi, L.O.; Kothmann, M.M. Effect of molecular weight and concentration of legume condensed tannins on in vitro larval migration inhibition of Haemonchus contortus. Vet. Parasitol. 2014, 199, 93-98.

20. Novobilský, A.; Stringano, E.; Hayot Carbonero, C.; Smith, L.M.J.; Enemark, H.L.; MuellerHarvey, I.; Thamsborg, S.M. In vitro effects of extracts and purified tannins of sainfoin (Onobrychis viciifolia) against two cattle nematodes. Vet. Parasitol. 2013, 196, 532-537.

21. Novobilský, A.; Mueller-Harvey, I.; Thamsborg, S.M. Condensed tannins act against cattle nematodes. Vet. Parasitol. 2011, 182, 213-220. 
22. Quijada, J.; Fryganas, C.; Ropiak, H.M.; Ramsay, A.; Mueller-Harvey, I.; Hoste, H. Anthelmintic activities against Haemonchus contortus or Trichostrongylus colubriformis from small ruminants are influenced by structural features of condensed tannins. J. Agric. Food Chem. 2015, 63, 6346-6354.

23. Williams, A.R.; Fryganas, C.; Ramsay, A.; Mueller-Harvey, I.; Thamsborg, S.M. Direct anthelmintic effects of condensed tannins from diverse plant sources against Ascaris suum. PLoS One 2014, 9(5): e97053. DOI: 10.1371/journal.pone.0097053

24. Hoste, H.; Torres-Acosta, J.F.J.; Quijada, J.; Chan-Pérez, J.I.; Dakheel, M.M.; Kommuru, D.S.; Mueller-Harvey, I.; Terrill, T.H. Interactions between nutrition and infections with Haemonchus contortus and related gastrointestinal nematodes in small ruminants. In: Gasser, R.B.; von Samson-Himmelstjerna, G. (Ed.), Haemonchus contortus and Haemonchosis - Past, Present and Future Trend. Elsevier Ltd, 2016, pp. 239-351.

25. Moreno-Gonzalo, J.; Manolaraki, F.; Frutos, P.; Hervás, G.; Celaya, R.; Osoro, K.; OrtegaMora, L.M.; Hoste, H.; Ferre, I. In vitro effect of heather (Ericaceae) extracts on different development stages of Teladorsagia circumcincta and Haemonchus contortus. Vet. Parasitol. 2013, 197:235-243.

26. Paolini, V.; Bergeaud, J.P.; Grisez, C.; Prevot, F.; Dorchies, P.; Hoste, H. Effects of condensed tannins on goats experimentally infected with Haemonchus contortus. Vet. Parasitol. 2003, 113, 253-261.

27. Paolini, V.; Frayssines, A.; Farge, F.; Dorchies, P. Effects of condensed tannins on established populations and on incoming larvae of Trichostrongylus colubriformis and Teladorsagia circumcincta in goats. Vet. Res. 2003, 34, 331-339. 
28. Desrues, O.; Mueller-Harvey, I.; Pellikaan, W.F.; Enemark, H.L.; Thamsborg, S.M. Condensed tannins in the gastrointestinal tract of cattle after sainfoin (Onobrychis viciifolia) intake and their possible relationship with anthelmintic effects. J. Agric. Food Chem. 2017, 65, 1420-1427.

29. Terrill, T.H.; Waghorn, G.C.; Woolley, D.J.; McNabb, W.C.; Barry, T.N. Assay and digestion of ${ }^{14} \mathrm{C}$-labelled condensed tannins in the gastrointestinal tract of sheep. Br. J. Nutr. 1994, 72, $467-477$.

30. Perez-Maldonado, R.A.; Norton, B.W. The effects of condensed tannins from Desmodium intortum and Calliandra calothyrsus on protein and carbohydrate digestion in sheep and goats. Br. J. Nutr. 1996, 76, 515-533.

31. Grabber, J.H.; Zeller, W.E.; Mueller-Harvey, I. Acetone enhances the direct analysis of procyanidin- and prodelphinidin-based condensed tannins in lotus species by the butanol-HCliron assay. J. Agric. Food Chem. 2013, 61, 2669-2678.

32. Gea, A.; Stringano, E.; Brown, R.H.; Mueller-Harvey, I. In situ analysis and structural elucidation of sainfoin (Onobrychis viciifolia) tannins for high-throughput germplasm screening. J. Agric. Food Chem. 2011, 59,495-503.

33 Azuhnwi, B.N.; Boller, B.; Dohme-Meier, F.; Hess, H.D.; Kreuzer, M.; Stringano, E.; MuellerHarvey, I. Exploring variation in proanthocyanidin composition and content of sainfoin (Onobrychis viciifolia). J. Sci. Food Agric. 2013, 93, 2102-2109.

34. Ramsay, A.; Drake, C.; Grosse Brinkhaus, A.; Girard, M.; Copani, G.; Dohme-Meier, F.; Bee, G.; Niderkorn, V.; Mueller-Harvey, I. Sodium hydroxide enhances extractability and analysis of proanthocyanidins in ensiled sainfoin (Onobrychis viciifolia). J. Agric. Food. Chem. 2015, 63, 9471-9479. 
35. Matthews, S.; Mila, I.; Scalbert, A.; Pollet, B.; Lapierre, C.; duPenhoat, C.; Rolando, C.; Donnelly, D.M.X. Method for estimation of proanthocyanidins based on their acid depolymerization in the presence of nucleophiles. J. Agric. Food Chem. 1997, 45, 1195-1201.

36. Pérez-Jiménez, J.; Torres, J.L. Analysis of non-extractable polyphenols in foods: the current state of the art. J. Agric. Food Chem. 2011, 59, 12713-12724.

37. Bindon, K.A.; Smith, P.A.; Holt, H.; Kennedy, J.A. Interaction between grape-derived proanthocyanidins and cell wall material. 2. Implications for vinification. J. Agric. Food Chem. 2010, 58, 10736-10746.

38. Le Bourvellec, C.; Bouchet, B.; Renard, C.M.G.C. Non-covalent interaction between procyanidins and apple cell wall material. Part III: Study on model polysaccharides. Biochim. Biophys. Acta-Gen. Sub. 2005, 1725:10-18.

39. van Leeuwen, P.; Jansman, A.J.; Wiebenga, J.; Koninkx, J.F.; Mowen, J.M. Dietary effects of faba-bean (Vicia faba L.) tannins on the morphology and function of the small-intestinal mucosa of weaned pigs. Br. J. Nutr. 1995, 73, 31-39.

40. Choy, Y.Y.; Quifer-Rada, P.; Holstege, D.M.; Frese, S.A.; Calvert, C.C.; Mills, D.A.; LamuelaRaventos, R.M.; Waterhouse, A.L. Phenolic metabolites and substantial microbiome changes in pig feces by ingesting grape seed proanthocyanidins. Food Funct. 2014, 5, 2298-2308.

41. Gedir, J.V.; Sporns, P.; Hudson, R.J. Extraction of condensed tannins from cervid feed and feces and quantification using a radial diffusion assay. J. Chem. Ecol. 2005, 31, 2761-2773.

42. Riaz, M.Q.; Südekum, K.H.; Clauss, M.; Jayanegara, A. Voluntary feed intake and digestibility of four domestic ruminant species as influenced by dietary constituents: A meta-analysis. Livest. Sci. 2014, 162, 76-85. 
452 43. Mena, P.; Calani, L.; Bruni, R.; Del Rio, D. Chapter 6 - Bioactivation of High-Molecular453 Weight Polyphenols by the Gut Microbiome. In: Diet-Microbe Interactions in the Gut (ed. Rio, 454 K. T. D.), Academic Press, San Diego, 2015, pp. 73-101.

455 44. Del Rio, D.; Calani, L.; Dall'Asta, M.; Brighenti, F. Polyphenolic composition of hazelnut skin. 456 J. Agric. Food. Chem. 2011, 59, 9935-9941.

457 45. Wang, Y.; Mc Allister, T.A.; Acharya, S. Condensed tannins in sainfoin: composition, 458 concentration, and effects on nutritive and feeding value of sainfoin forage. Crop Sci 2015, 55, 13-22.

46. Stringano, E.; Hayot Carbonero, C.; Smith, L.M.J.; Brown, R.H.; Mueller-Harvey, I. Proanthocyanidin diversity in the EU "HealthyHay" sainfoin (Onobrychis viciifolia) germplasm collection. Phytochemistry 2012, 77, 197-208.

47. Spiegler, V.; Liebau, E.; Hensel, A. Medicinal plant extracts and plant-derived polyphenols with anthelmintic activity against intestinal nematodes. Nat. Prod. Rep. 2017, 34, 627-643.

48. Li, M.; Hagerman, A.E. Interactions between plasma proteins and naturally occurring polyphenols. Curr. Drug Metab. 2013, 14, 432-445.49. Arroyo-Lopez, C.; Manolaraki, F.; experimental trickle infections with Haemonchus contortus and Trichostrongylus colubriformis. Parasite 2014, 21, 71-80.

\section{$471 \quad$ Funding}

472 The research was funded by the European Commission through the PITN-GA-2011-289377 473 "LegumePlus" project. 
Table 1. Mean ( ${ } \mathrm{SD})$ Concentrations of Condensed Tannin (g CT/100 g DW) Measured Either With the Acetone-HCl-butanol or the Thiolysis Assays in Feeds, Digesta and Fecal Samples from Each Experimental Group (n= 5 lambs).

\begin{tabular}{|c|c|c|c|c|c|}
\hline & Feed & Rumen & Abomasum & $\begin{array}{c}\text { Small } \\
\text { Intestine }\end{array}$ & Feces \\
\hline \multicolumn{6}{|l|}{ Acetone-HCl-butanol assay } \\
\hline Sainfoin pellets group & $6.5 \pm 0.3^{a}$ & $1.0 \pm 0.1^{b}$ & $2.1 \pm 0.3^{c^{*}}$ & $1.8 \pm 0.3^{b}$ & $2.0 \pm 0.4^{b}$ \\
\hline Hazelnut skin group & $5.1 \pm 0.1^{a}$ & $1.1 \pm 0.1^{b}$ & $1.7 \pm 0.2^{b c}$ & $1.2 \pm 0.1^{b c}$ & $2.0 \pm 0.3^{c *}$ \\
\hline \multicolumn{6}{|l|}{ Thiolysis assay } \\
\hline Sainfoin pellets group & $1.7 \pm 0.1^{\mathrm{a}^{* *}}$ & $0.3 \pm 0.1^{b}$ & $0.7 \pm 0.1^{c *}$ & $0.4 \pm 0.1^{b c}$ & $0.4 \pm 0.1^{b}$ \\
\hline Hazelnut skin group & $6.3 \pm 0.1^{\mathrm{a}^{* *}}$ & $0.5 \pm 0.1^{b}$ & $0.7 \pm 0.1^{b}$ & $0.4 \pm 0.1^{b}$ & $0.7 \pm 0.1^{b}$ \\
\hline
\end{tabular}


Table 2. Condensed Tannin Compositions in Digesta or Fecal Samples from Lambs $(n=5)$

Fed with either Sainfoin Pellets or Hazelnut Skins.

\begin{tabular}{|c|c|c|c|}
\cline { 2 - 4 } \multicolumn{1}{c|}{} & mDP & PD/PC \% & cis/trans-flavan-3-ols \% \\
\hline Sainfoin pellets & $11.5 \pm 0.3$ & $74.8 / 25.2( \pm 0.5)$ & $85.3 / 14.7( \pm 0.1)$ \\
\hline Rumen & - & $79.5 / 20.5( \pm 0.9)$ & $87.9 / 12.1( \pm 0.7)$ \\
\hline Abomasum & - & $84.1 / 15.9( \pm 0.50$ & $91.3 / 8.7( \pm 0.5)$ \\
\hline Small intestine & - & $78.7 / 21.3( \pm 1.1)$ & $87.5 / 12.5( \pm 0.3)$ \\
\hline Feces & - & $72.4 / 27.6( \pm 1.6)$ & $88.9 / 11.1( \pm 1.3)$ \\
\hline Hazelnut skin & $13.3 \pm 0.1$ & $27.9 / 72.1( \pm 0.2)$ & $58.4 / 41.6( \pm 0.2)$ \\
\hline Rumen & $14.8 \pm 0.7$ & $34.3 / 65.7( \pm 1.5)$ & $46.3 / 53.7( \pm 1.2)$ \\
\hline Abomasum & $13.9 \pm 0.3$ & $33.4 / 66.6( \pm 0.7)$ & $51.3 / 48.7( \pm 0.6)$ \\
\hline Small intestine & $13.8 \pm 1.2$ & $33.4 / 66.6( \pm 1.7)$ & $46.9 / 53.1( \pm 2.3)$ \\
\hline Feces & $13.2 \pm 0.3$ & $18.9 / 81.1( \pm 2.4)$ & $48.4 / 51.6( \pm 0.6)$ \\
\hline
\end{tabular}

Note: there were no significant differences between the different organs.

Abbreviations: mean degree of polymerization (mDP); \% refers to molar percentages of procyanidins (PC), prodelphinidins (PD), cis- or trans- flavan-3-ols (cis or trans); \pm refers to standard deviations 
Table 3. Molar Percentages (\%) of Terminal and Extension Flavan-3-ol Subunits within CT from Digesta and Fecal Samples Collected from Lambs that Had Been Fed with Sainfoin Pellets or Hazelnut Skins.

\begin{tabular}{|c|c|c|c|c|c|c|c|c|c|c|}
\hline & \multicolumn{4}{|c|}{ Terminal units (\%) } & \multicolumn{5}{c|}{ Extension units (\%) } \\
\cline { 2 - 12 } & GC & EGC & C & EC & GC-BM & EGC-BM & C-BM & EC-BM & $\begin{array}{c}\text { ECg- } \\
\text { BM }\end{array}$ & $\begin{array}{c}\text { EGCg- } \\
\text { BM }\end{array}$ \\
\hline Sainfoin pellets & $2.4 \pm 0.1$ & $1.8 \pm 0.1$ & $1.9 \pm 0.1$ & $2.7 \pm 0.1$ & $9.5 \pm 0.3$ & $61.2 \pm 0.5$ & $0.9 \pm 0.1$ & $19.7 \pm 0.3$ & 0.0 & 0.0 \\
\hline Rumen & 0.0 & 0.0 & 0.0 & 0.0 & $10.3 \pm 0.5$ & $69.2 \pm 1.5$ & $1.7 \pm 0.1$ & $18.8 \pm 0.9$ & 0.0 & 0.0 \\
\hline Abomasum & 0.0 & 0.0 & $1.3 \pm 0.0$ & $1.2 \pm 0.0$ & $8.3 \pm 0.3$ & $75.7 \pm 0.7$ & $0.6 \pm 0.0$ & $15.4 \pm 0.5$ & 0.0 & 0.0 \\
\hline Small intestine & 0.0 & 0.0 & $0.0 \pm 0.0$ & $1.9 \pm 0.0$ & $11.9 \pm 0.3$ & $66.7 \pm 1.5$ & $0.5 \pm 0.0$ & $19.8 \pm 1.9$ & 0.0 & 0.0 \\
\hline Feces & 0.0 & 0.0 & $2.5 \pm 0.2$ & $2.3 \pm 0.2$ & $10.1 \pm 0.7$ & $62.3 \pm 2.2$ & 0.0 & $24.8 \pm 1.1$ & 0.0 & 0.0 \\
\hline Hazelnut skins & 0.0 & 0.0 & $7.5 \pm 0.1$ & 0.0 & $12.1 \pm 0.1$ & $15.1 \pm 0.1$ & $21.2 \pm 0.1$ & $39.4 \pm 0.3$ & $0.8 \pm 0.1$ & $3.9 \pm 0.1$ \\
\hline Rumen & 0.0 & 0.0 & $6.8 \pm 0.2$ & 0.0 & $20.1 \pm 1.5$ & $14.3 \pm 0.3$ & $26.8 \pm 0.6$ & $31.9 \pm 1.1$ & 0.0 & 0.0 \\
\hline Abomasum & 0.0 & 0.0 & $6.5 \pm 0.1$ & $0.7 \pm 0.1$ & $16.3 \pm 0.6$ & $17.2 \pm 0.2$ & $25.9 \pm 0.6$ & $33.5 \pm 0.4$ & 0.0 & 0.0 \\
\hline Small intestine & 0.0 & 0.0 & $7.5 \pm 0.8$ & 0.0 & $17.8 \pm 0.5$ & $15.6 \pm 1.4$ & $27.8 \pm 1.7$ & $31.4 \pm 1.1$ & 0.0 & 0.0 \\
\hline Feces & 0.0 & 0.0 & $7.6 \pm 0.2$ & 0.0 & $10.1 \pm 1.7$ & $8.8 \pm 0.9$ & $34.0 \pm 1.0$ & $39.5 \pm 1.3$ & 0.0 & 0.0 \\
\hline
\end{tabular}

Abbreviations: Gallocatechin (GC), epigallocatechin (EGC), catechin (C), epicatechin (EC), epicatechin gallate (ECg), epigallocatechin gallate (EGCg), benzyl mercaptan adduct (-BM); \pm refers to standard deviations 
Table of content (TOC)

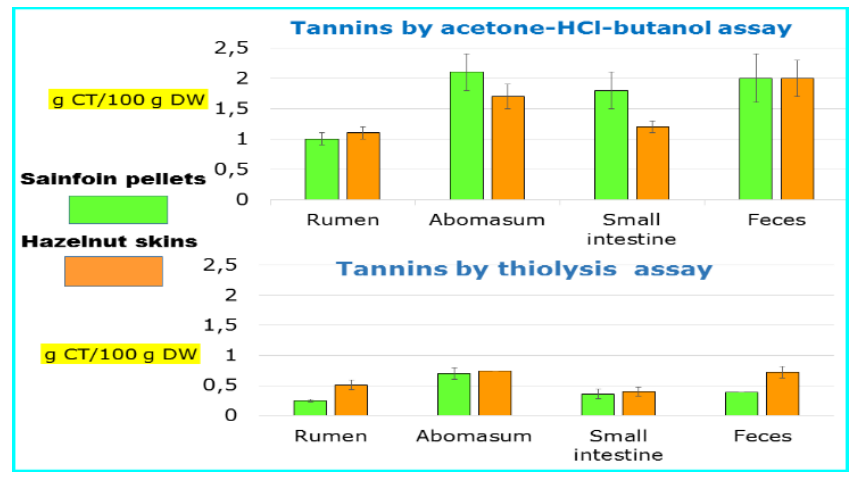

